\title{
Parametric evaluation of emission savings potential based on a mobility demand model
}

\author{
M. Kugler \& M. Lienkamp \\ Institute of Automotive Technology, \\ Technische Universität München, Germany
}

\begin{abstract}
Considering an intelligent optimization of individual mobility-induced $\mathrm{CO}_{2}$ emissions, the usage of renewable energies in electric vehicles is obvious. Unfortunately, renewable energies are not as consistent in their availability over the day and over the seasons as conventional energies based on oil and gas. For this reason, the energy generated by renewable sources would have to be buffered in special energy storage systems for later usage. But not all customers relish the idea of installing a voluminous temporary storage system in their homes.

In our approach we take a model based generic mobility demand of the everyday mobility behaviour as a basis for evaluating the emission savings potential for a household. For that aim a high usage factor of the energy generated by a home-integrated photovoltaic system (PV) is crucial. This work presents the optimisation process for determining the optimal configuration of the PV, buffer system and electric vehicle (EV) relative to the respective mobility characteristics. In order to evaluate the emission savings, the optimisation also proceeds with regard to cost-effectiveness considerations. This is conducted in a two-layered assessment. First, the technical costs for all installations are considered. Then, based on survey results, subjective userdependent factors are integrated.

The results show that the emission savings potential ranges up to $90 \%$ of everyday mobility behaviour, taking different EVs as a basis for the mobility demand model. Relating to a compact car, an average savings potential of $75 \%$ is realistic. The main contributor for increasing the savings is the buffer storage system, allowing for emission-neutral recharging at all times.

Keywords: $\mathrm{CO}_{2}$, emission savings, mobility behaviour, photovoltaic system.
\end{abstract}




\section{Introduction}

Decreasing $\mathrm{CO}_{2}$ emissions is a goal highly relevant not only in politics, but also for industries as well as private consumers. The Intergovernmental Panel on Climate Change (IPCC) [1] states that emissions effected especially by the transportation sector constitute approximately one quarter of the total emission output. Considering the increasing mobility and transport demand in developing countries - most notably in Asian or South American nations - a solution to effectively lowering $\mathrm{CO}_{2}$ emissions is necessary. According to Creutzig et al. [2] a decrease of transportation induced $\mathrm{CO}_{2}$ emissions can be achieved by reducing the overall transportation demand, optimizing the energy efficiency in transport or reducing the amount of carbon in fuel. However, in the private sector a reduction of transportation antagonizes the basic need of mobility, which shapes the future energy demand as predicted by Wolf [3]. That leads to a higher importance of alternative fuels and a more enhanced or intelligent mobility behaviour. The integration of electric vehicles (EV) in the everyday mobility demand presents not only a solution concerning a better carbon balance caused by transportation. Based on electricity being the propulsion energy, renewable energies can be used for charging EVs. Wirth and Schneider [4] observe that the energy generated by already existing photovoltaic systems (PV) in Germany provided 7.5\% of the total German energy demand in 2015 and can cover up to $50 \%$ of the current energy demand. Wagner et al. [5] show that combining PV energy and electromobility is a valuable approach to effectively reducing carbon emissions. Wesselak and Voswinckel [6] describe that the energy generated by PV is strongly subjected to variation attributable to weather influences, seasonal differences as well as constructional circumstances. Those variations affect the charging capabilities and require further solutions in managing the energy efficiently. Managing the energy balance of a household by linking the energy consumption with the energy generation by the PV influences the private consumption ratio. A solution to raising this ratio is the implementation of a buffer system that saves the energy generated by the PV system temporarily and provides this energy at all times. Nobis et al. [7] show that the combination of EV and buffer systems increases the private consumption ratio from $78 \%$ up to $94 \%$, influenced especially by the availability of a buffer system.

\section{Mobility model describing emissions}

During the project study, a subject group of 52 participants out of 20 families was provided with smart phones for mobility tracking purposes. The smart phones were equipped with an application where the individual users had to actively track their mobility behaviour. This tracking methodology is described in Kugler et al. [8]. Over a project time of 12 months all participants tracked approximately 200,000 kilometres. As shown in Kugler et al. [9], the mobility demand was mainly confined to the vicinity of around 50 kilometres around the project home town - Garmisch-Partenkirchen in Southern Bavaria, a rural 
environment where all daily needs can be provided for in close proximity. By connecting the data from all users of one family, the overall demand for mobility for a family can be depicted.

The generated and clustered raw data is used for the determination and prediction of the average mobility demand. The raw data is analysed and the characteristic mobility demand is determined dependent on the time of day and the constellation of the family. Here it is not important which actual ways the family members are travelling, but rather what distance demand arises at which time intervals. Furthermore, the length of those time intervals, in which a trip can be started, is linked to the reason of mobility demand, e.g., a trip to school or work disposes of a shorter time interval than a trip for running private errands. The probability of a trip being integrated in the mobility demand is determined by weight. Kugler et al. [9] deduced the weight of a mobility trip by the consistency rate of similar trips. Taking that information into account and focusing on everyday mobility, a mobility demand model for each family is derived.

Based on the probable mobility behavior, the emissions caused by mobility can be described. As the mobility model itself is of a qualitative type - only describing the occurrence of trips, not the velocity profile in detail - a straightforward translation on mobility into emissions is applicable. For this, the emission data per $100 \mathrm{~km}$ is used. In order to evaluate the emission potential in different cases, several EV configurations are considered. Those configurations are based on the real driving performance values tested by ADAC and are shown in Table 1.

Table 1: Vehicle parameterizations for emission savings analysis (real energy consumption).

\begin{tabular}{|c|c|c|c|c|}
\hline & $\begin{array}{c}\text { Mitsubishi } \\
\text { i-MiEV [10] }\end{array}$ & BMW i3 [11] & VW e-Golf [12] & Tesla Model S [13] \\
\hline $\begin{array}{c}\text { Consumption } \\
\left(\frac{\mathrm{kWh}}{100 \mathrm{~km}}\right)\end{array}$ & 16.9 & 16.7 & 18.8 & 24.2 \\
\hline $\begin{array}{c}\text { Battery capacity } \\
(\mathrm{kWh})\end{array}$ & 16.0 & 18.8 & 24.2 & 85.0 \\
\hline
\end{tabular}

\section{Methodology}

\subsection{Mobility analysis}

Ensuing from the mobility demand model describing a reference week of the mobility demand for each family, a detailed analysis is conducted. Thereby, the first characteristic information qualifying the mobility behaviour is revealed to be the weekly mileage. The families taking part in the field study varied from mileages of about $100 \mathrm{~km}$ up to $600 \mathrm{~km}$ per week for everyday mobility (Table 2). Since the mobility demand is not sufficiently specified by the general summative mobility demand, the probability for charging the EV is evaluated. 
For this purpose, the probable charging time is assessed according to the vehicle being at home in between trips.

Figure 1 shows that the possibility of charging the EV is strongly diminished during the daytime hours, because the vehicle is used for driving or is parked elsewhere but at home. This indicates a reduced potential of charging the EV directly via the PV system, because the peak energy generation is reached around midday, due to the optimal position of the sun. Taking into account the relatively short distances of the trips in detail, as stated by Kugler et al. [9], the mobility demand can be directly connected to the state of charge (SOC) of the battery.

Table 2: Weekly mileage driven by each family according to the mobility demand model.

\begin{tabular}{|c|c|c|c|c|c|c|c|c|c|c|c|}
\hline Family ID & 6 & 4 & 5 & 14 & 10 & 7 & 13 & 11 & 15 & 17 & 12 \\
\hline $\begin{array}{c}\text { Weekly } \\
\text { mileage }(\mathrm{km})\end{array}$ & 107 & 115 & 118 & 124 & 126 & 130 & 147 & 197 & 499 & 588 & 598 \\
\hline
\end{tabular}

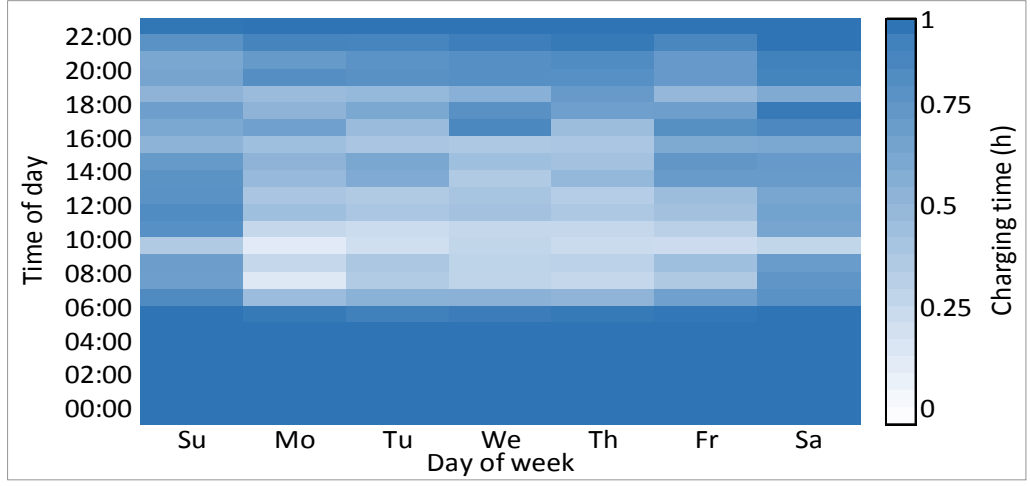

Figure 1: Probability of charging the EV dependent on time of day as well as day of week, average of all families.

For determining the SOC distribution, a 3-week-simulation based on the mobility demand model is conducted. The SOC is reduced according to the EV configuration during trips and charging with $3.7 \mathrm{~kW}$ takes place during stops at home that are longer than half an hour. The SOC results of the third week are analysed and depicted in Figure 2. The results show that it is not necessary to recharge the EV every time and thus present more flexibility in the charging schedule and consequently in the emission savings potential.

\subsection{Optimization of configuration}

The emission savings potential strongly relies on the dimensioning of the PV system, as well as the possibility to store energy temporarily, because the mobility demand is anticyclical to the energy generation. Therefore, an optimal 


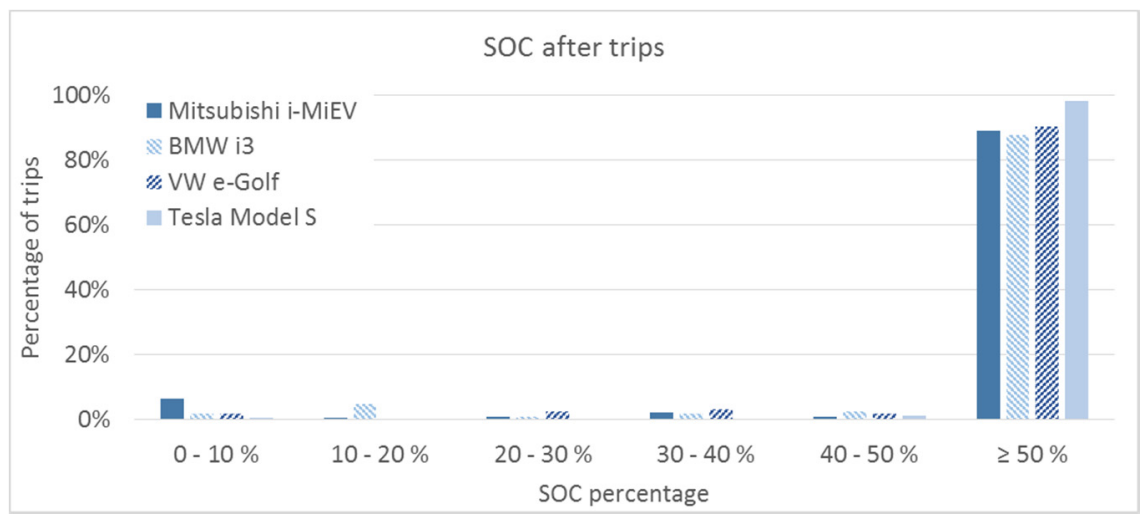

Figure 2: SOC distribution of different EV based on the mobility demand model.

configuration of the PV system and the buffer system is needed. Figure 3 shows the general methodical approach of coordinating the mobility schedule with the $\mathrm{PV}$ and buffer installation. In a successive procedure, the emission values for reasonable PV-buffer-constellations are calculated. The maximum size for the $\mathrm{PV}$-system is set to $150 \mathrm{~m}^{2}$, the buffer size is limited to $20 \mathrm{kWh}$. Those limits are chosen due to technical limitations found in private homes.

A maximum dimensioning does not represent a reasonable or affordable solution. Hence, the emission savings potential is evaluated also for an $85 \%$ as well as a $95 \%$ solution, taking cost-effectiveness considerations into account.

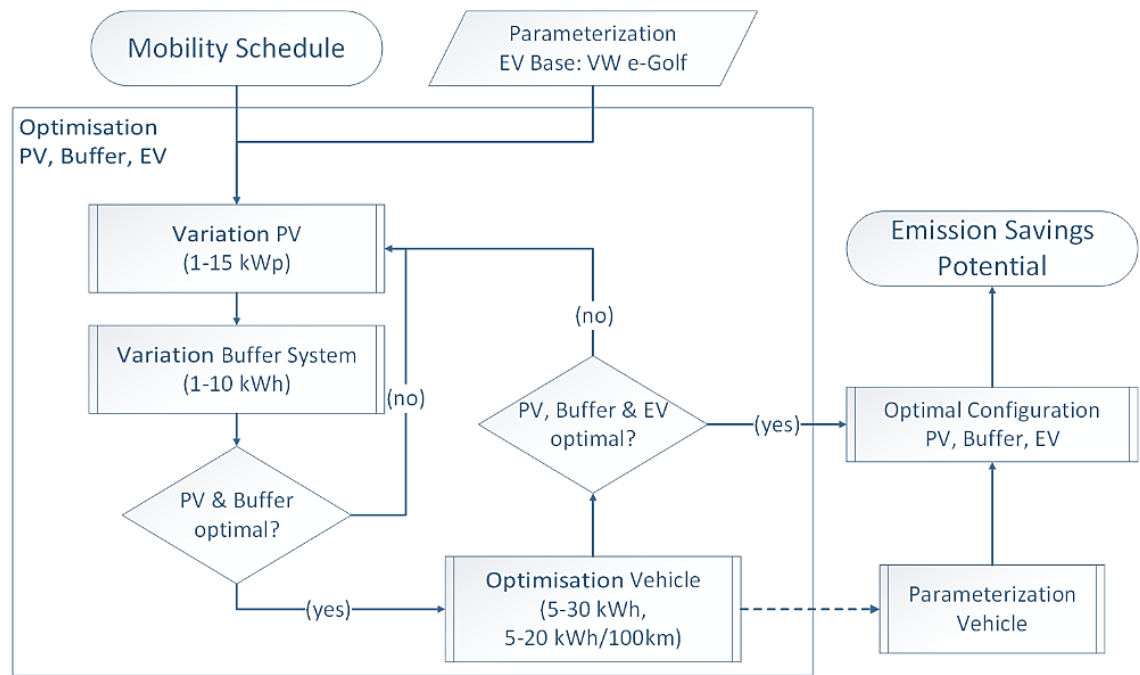

Figure 3: Methodical approach for the deduction of the emission savings potential dependent on a generic mobility demand schedule. 
Furthermore, the investment costs of the PV and buffer system figure into the optimal configuration and saving potential. For the evaluation, the following average values are assumed:

- PV system: $211 €$ per $\mathrm{m}^{2}$ in 2015 (Fendrich [14], Reuter [15]);

- Buffer system: $2073 €$ per kWh in 2016 (Schmitz [16]).

Based on those values, an approximate ratio describing PV to buffer of 1:10 considering the investment costs is assumed. According to this approach, the emissions effected by the mobility demand carried out by an EV and influenced by different PV-buffer-configurations can be evaluated.

\section{Evaluation of emission savings potential}

Electromobility is a highly user-dependent and emotional topic, due to the reduced mobility freedom caused by the limited range of EVs and the higher purchasing prices. As a consequence the emission savings potential is not only assessed from the technical point of view, but also according to the willingness to invest in PV and buffer system.

\subsection{Theoretical emission savings}

In order to evaluate the emission savings potential, all families are assessed according to their maximum savings potential. The maximum savings potential is defined as follows: All trips that lie within the range of the respective EV (trips with a too short stop time in between are considered as connected trips) have to be realised by the EV and the EV is charged exclusively with energy generated by the PV system.

Concerning the savings potential, Figure 4 displays two dependencies:

- The vehicle type, meaning the interaction between consumption and battery capacity of the EV, strongly influences the necessary buffer size due to the amount of energy stored for recharging.

- A strong dependency also exists between the buffer size and the weekly mileage of the family, because longer distances during daytime lead to a lower SOC. The energy then has to be recharged in the evening.

The boundary value exceeding the limit is caused by the previously defined buffer limit of $20 \mathrm{kWh}$ and the increased energy demand in the early evening for recharging purposes. Thus, a compensation by exceedingly increasing the PV area is necessary.

Additionally, to the maximum savings the constellations for $85 \%$ and $95 \%$ emission savings are evaluated. The saving potential is highly influenced by the buffer size and less by the PV area size (Figure 5). The weekly mileage described by the mobility demand model features strongly. The compensation of increased energy demand by PV area due to the buffer restrictions is once more discernible. According to the results the stronger correlation between emission savings and the mobility demand is defined by the buffer size. Since the buffer is the more expensive part in the PV-buffer-constellation, an assessment of the $\mathrm{CO}_{2}$ emissions depending on buffer size variation is necessary. For this analysis, the 


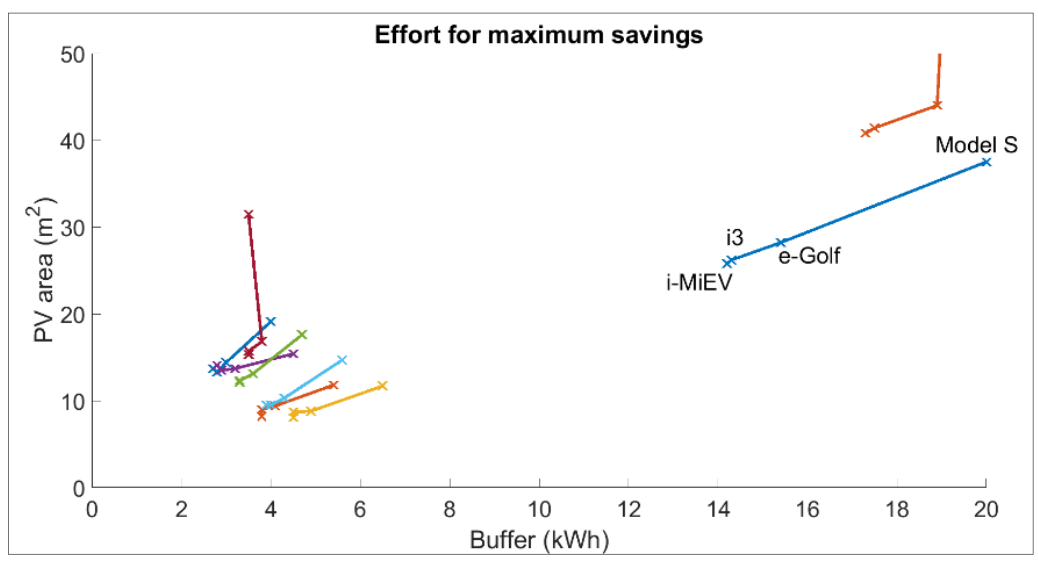

Figure 4: PV-buffer constellations for different families (colours) realising the maximum emission savings dependent on different EVs.

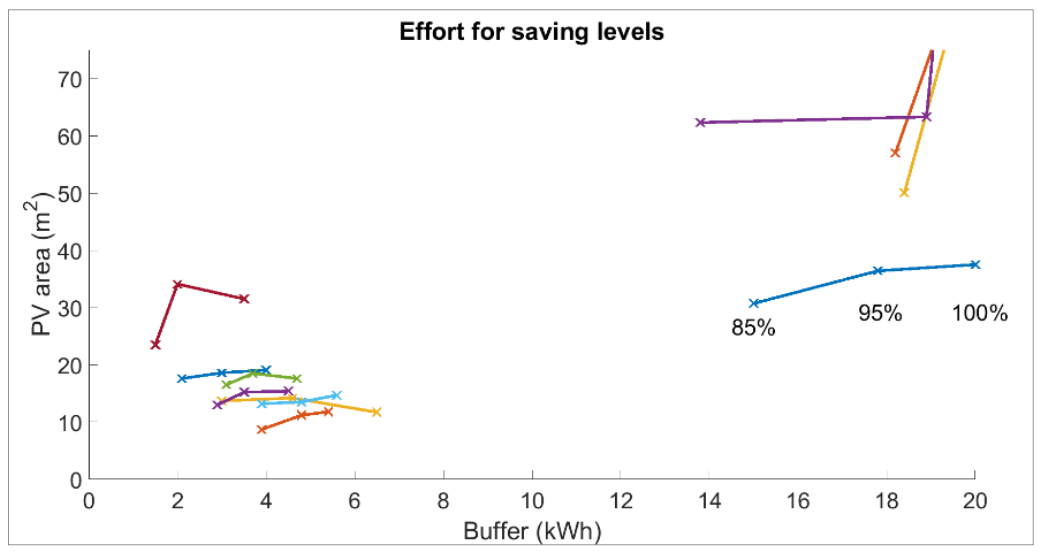

Figure 5: PV-buffer constellations for different families (colours) showing the difference between the $85 \%, 95 \%$ as well as optimum (100\%) saving level.

weekly emissions are calculated based on the existing PV systems of all families in combination with varied buffer sizes from $0 \mathrm{kWh}$ up to $4 \mathrm{kWh}$ (Figure 6). Especially families with relatively low weekly mileage can reach emission neutral mobility. This can be realized with an additional buffer of only $3 \mathrm{kWh}$.

Considerably higher mileages or notably smaller PV systems - like family 11 with only $12 \mathrm{~m}^{2}$ PV area - can reduce their emissions, but need larger buffer systems for emission neutral mobility. A scatter analysis for evaluating the correlation between additional saved energy and additional buffer capacity factoring all families, all saving levels as well as all EV types is shown in Figure 7. An increase of buffer size leads to additional saved energy, raising the ratio of used $\mathrm{PV}$ energy for charging the $\mathrm{EV}$. 


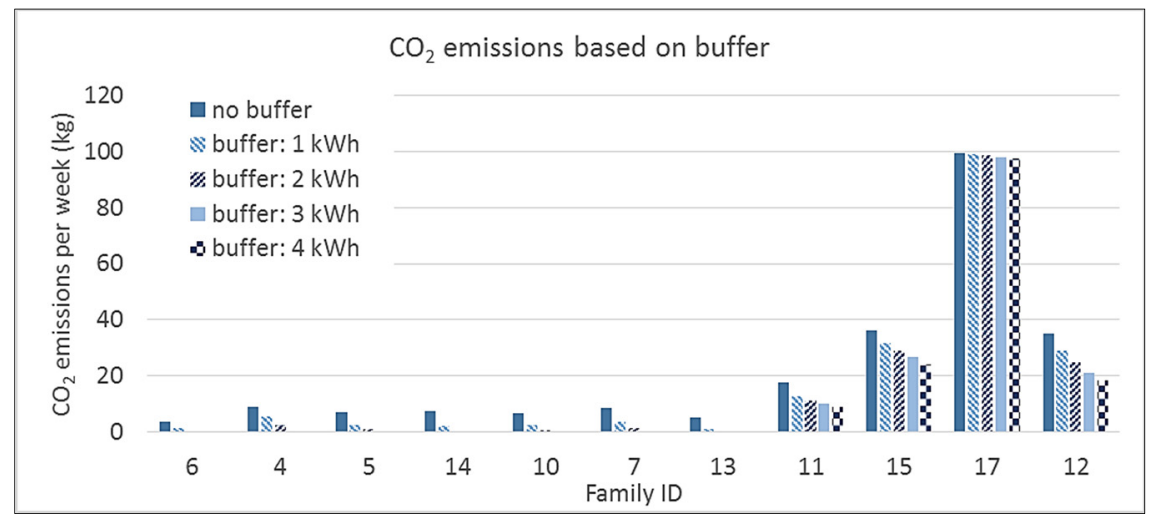

Figure 6: Weekly mobility emissions with BMW i3 and reduction potential through buffer systems with existing PV installations.

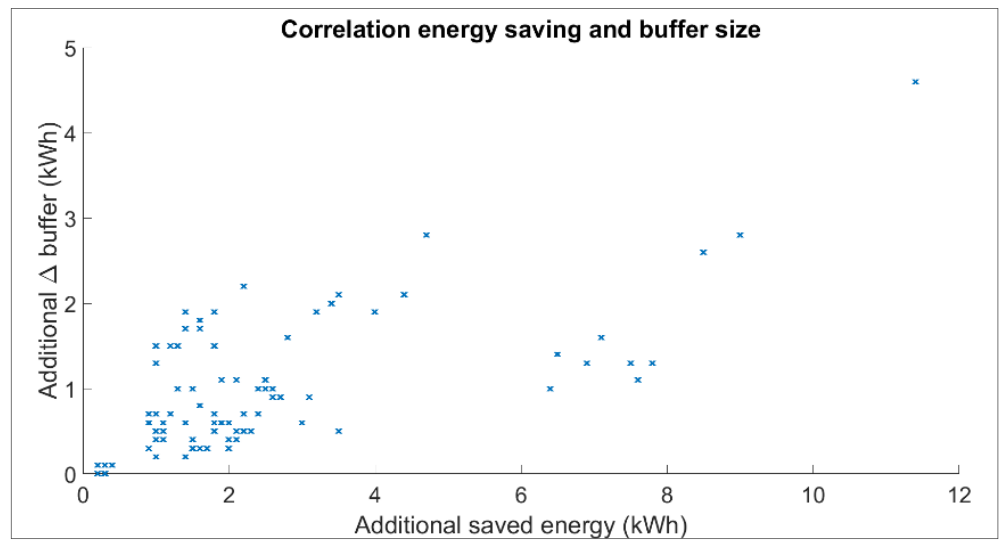

Figure 7: Correlation between buffer size and saved energy.

Concluding the evaluation of the theoretical emission savings, based on the mobility demand, a four-step-potential is outlined in Table 3. Thereby, the emission reduction is based on the emissions caused by a conventional vehicle and the mobility demand. The conventional vehicle emissions are considered with $18.2 \mathrm{~kg} \mathrm{CO}_{2}$ per $100 \mathrm{~km}$, according to Hensler [17].

Table 3: Average emission savings potential for different vehicle types. Only mobility induced emissions are considered; no production emissions.

\begin{tabular}{|c|c|c|c|c|}
\hline \multicolumn{2}{|c|}{} & Minicar & Golf class & Luxury vehicle \\
\hline $\begin{array}{c}\text { Average } \\
\text { reduction } \\
\text { potential based } \\
\text { on a }\end{array}$ & Standard electricity mix & $26 \%$ & $31 \%$ & $14 \%$ \\
\cline { 2 - 5 } $\begin{array}{c}\text { conventional } \\
\text { vehicle }\end{array}$ & Optrent installation & $37 \%$ & $48 \%$ & $34 \%$ \\
\cline { 2 - 5 } & Maximum installation & $65 \%$ & $74 \%$ & $79 \%$ \\
\hline
\end{tabular}


The current installations consist only of the existing PV systems. The optimum installations implement the $85 \%$ saving solution. Because trips that lie beyond the range of the EVs still have to be realised by a conventional vehicle, the average reduction potentials are lower than $85 \%$. As an example, Figure 8 shows the four-step-potential for the BMW i3, which is represented in the Golf class. The current installations already reduce the emissions notably. Also, the difference between optimum and maximum installation is negligibly. Only family 17 cannot reduce the emissions significantly, due to several trips longer than the range of the EV. This can be solved with increasing ranges of future EVs.



Figure 8: Emission savings potential for BMW i3 based on a $3.7 \mathrm{~kW}$ charging station.

Projecting the emission savings per week and taking the average of all families, a potential of up to $2 \mathrm{t} \mathrm{CO}_{2}$, which can be saved by year, is estimated (as shown in Figure 9).

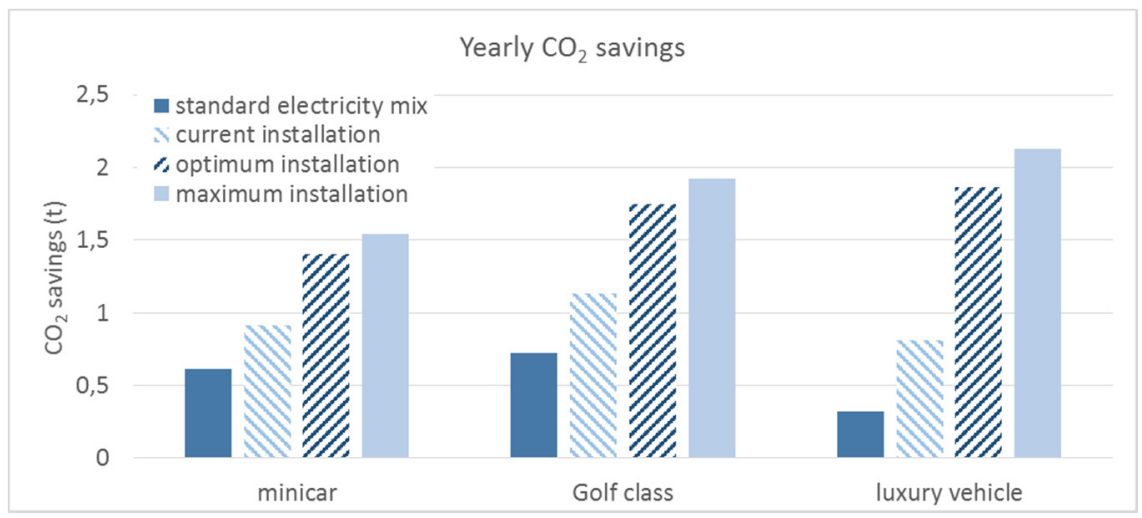

Figure 9: Projected average $\mathrm{CO}_{2}$ savings per year and household dependent on the vehicle type. 


\subsection{User-dependent emission savings}

Theoretical savings always have to be set into relation to the practical realization. In the case of a strong dependency on expensive installations like the buffer system, the user-dependent acceptance and willingness to pay has to be taken into account. For this purpose a publicly accessible user survey with 51 questions and 80 participants was conducted. Figure 10 shows the overall user-acceptance regarding the usage of an EV in combination with a PV-buffer-system in order to increase the private consumption ratio is positive. The high expenses are the main factors preventing the immediate realization. Considering the user willingness to use an EV for the everyday mobility demand, Figure 11 reveals a strong tendency to also use solar energy for increasing the emission-free ratio. Approximately $40 \%$ of the survey participants tend to accept a mainly emissionfree solution. Therefore, the optimum installations, assuring average emission savings of up to $79 \%$ (Table 3 ), are a reasonable solution. Figure 12 outlines the cost scales for installing the optimum and maximum PV-buffer-constellations. Especially for the optimum solution based on an existing PV system, the expenses range around $5000 €$ for families with weekly mobility demands of up to $150 \mathrm{~km}$. Higher demands have to be compensated through larger buffer systems. The higher costs for those systems run up the price for the installations.

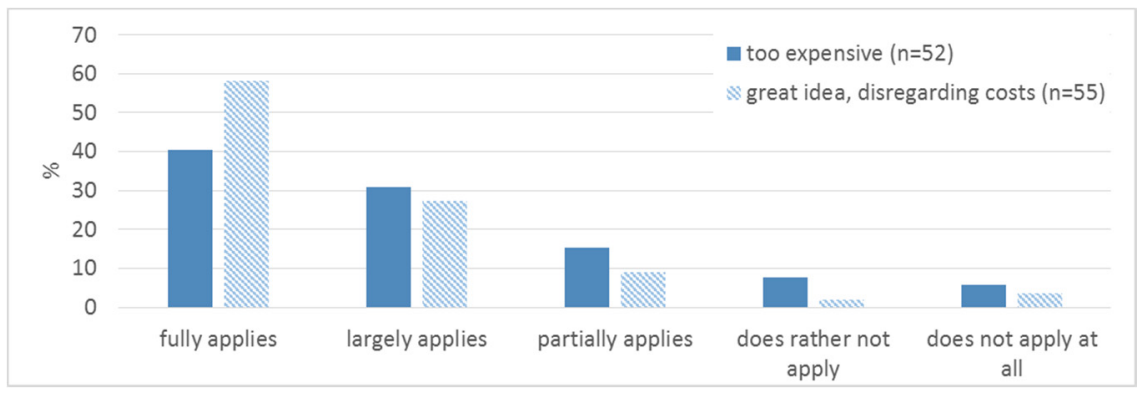

Figure 10: Assessment to user an EV with a PV-buffer-system in order to reduce emissions significantly.

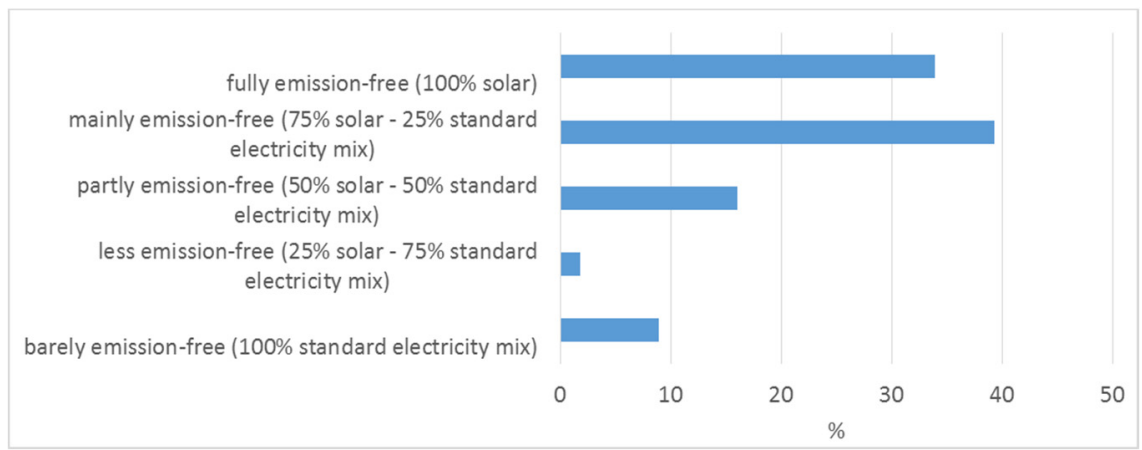

Figure 11: Willingness to conduct EV mobility emission-free $(n=56)$. 


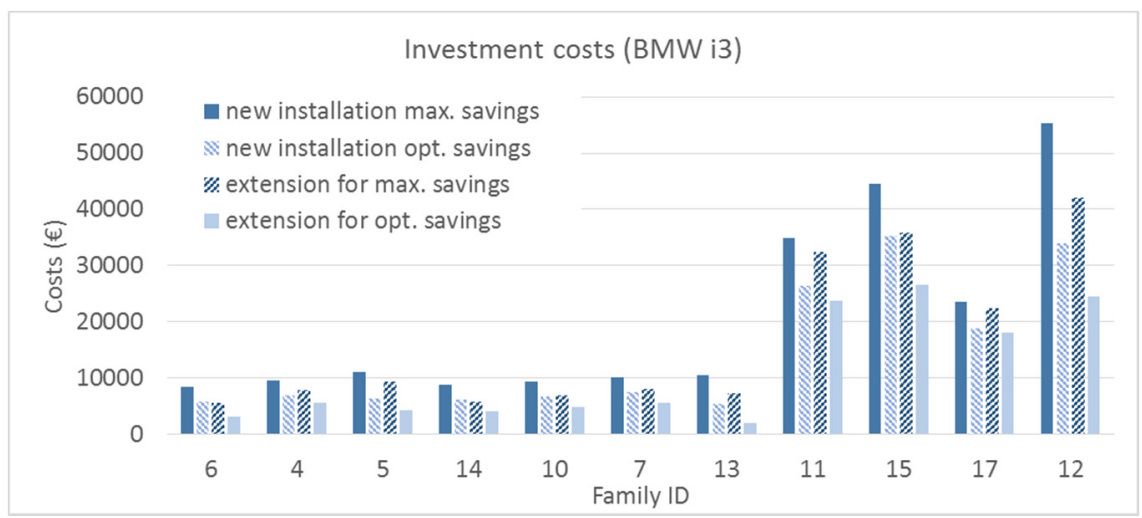

Figure 12: Expectable costs for maximum and optimum savings for extending existing PV systems and new installations based on BMW i3.

\section{Conclusion}

As the evaluation of the theoretical and the user-dependent emission savings shows, there is a high potential of reducing $\mathrm{CO}_{2}$ emissions by charging an EV through PV generated energy. It is shown, that buffer systems strongly influence the saving level. With falling prices for buffer storage, the obstacle to invest in a buffer system is supposed to decline. The resulting emission potentials can already be considered economical for households with small mobility ranges. As concluded in Kugler et al. [9], the emission potentials promise nearly emissionfree mobility especially through the realization through second cars.

In this new approach the evaluation of the emissions is based on an individual mobility demand model. Therefore, the potential assessment is qualitative. In future works the results can be transferred to further households. First comparisons can be premised on the clustered mobility demand scales.

Concluding this work, a high emission potential in everyday mobility demand can be attested. The combination of EVs with renewable energy generated at home is contributing significantly to the emission reduction aims.

\section{Acknowledgements}

M. Kugler initiated the idea of the paper and contributed to design, functional development and implementation of the system.

M. Lienkamp made an essential contribution to the conception of the research project. He revised the paper critically for important intellectual content. He gave final approval of the version to be published and agrees to all aspects of the work. As a guarantor, he accepts responsibility for the overall integrity of the paper.

This paper contains results of the theses from F. Bock and B. Bencsik. The authors would like to thank them for their contributions. 
This work was conducted within the eGAP Modellkommune Elektromobilität Garmisch-Partenkirchen project, funded by the Bavarian State Ministry of Economics and Media, Energy and Technology.

\section{References}

[1] IPCC, Climate Change 2014: Mitigation of Climate Change. Contribution of Working Group III to the Fifth Assessment Report of the Intergovernmental Panel on Climate Change, Cambridge University Press, 2015.

[2] F. Creutzig, P. Jochem, O. Edelenbosch, L. Mattauch, D. Vuuren, D. McCollum and J. Minx, "Transport: A roadblock to climate change mitigation?," Science, vol. 350, no. 6263, pp. 911-912, 2015.

[3] B. Wolf, "Wohnen und Mobilität: Die Zukunft der Energieversorgung," Moderne Elektronik im Kraftfahrzeug IV, vol. 4, p. 1, 2009.

[4] H. Wirth and K. Schneider, "Aktuelle Fakten zur Photovoltaik in Deutschland," Fraunhofer ISE, 2015.

[5] M. Wagner, K. Schönsteiner and T. Hamacher, "Impacts of Photovoltaics and Electromobility on the Singaporean Energy Sector," Energy Procedia, pp. 126-134, 2012.

[6] V. Wesselak and S. Voswinckel, Photovoltaik - Wie Sonne zu Strom wird, Springer Berlin Heidelberg, 2012.

[7] P. Nobis, F. Samweber and S. Fischhaber, "PV-Eigenverbrauch mit Elektrofahrzeugen und Hausspeichersystemen," in IEWT Wien 2015, 2015.

[8] M. Kugler, S. Osswald, C. Frank and M. Lienkamp, "Mobility tracking system for $\mathrm{CO}_{2}$ footprint determination," in Proceedings of the 6th International Conference on Automotive User Interfaces and Interactive Vehicular Applications, 2014.

[9] M. Kugler, S. Osswald, C. Frank and M. Lienkamp, "Assessment of Electromobility in Non-Urban Environments," in CoFAT, 2015.

[10] M. Ruhdorfer, "ADAC Autotest: Mitsubishi i-MiEV," ADAC e.V., 2011.

[11] M. Brand, “ADAC Autotest: BMW i3," ADAC e.V., 2013.

[12] S. Giuliani, “ADAC Autotest: VW e-Golf,” ADAC e.V., 2014.

[13] D. Silvestrod, "ADAC Autotest: Tesla Model S Performance," ADAC e.V., 2013.

[14] J. Fendrich, "Energie-Atlas Bayern - Mischpult Energiemix Bayern vor Ort," Bayrisches Landesamt für Umwelt, 2014. [Online]. Available: https://www.energieatlas.bayern.de/kommunen/mischpult.html [accessed 27 January 2016].

[15] M. Reuter, "Photovoltaik-Preismonitor Deutschland," EuPD Research, 2013.

[16] J. Schmitz, "Solaranlagenportal.de" 2015. [Online]. Available: https://solaranlagen-portal.de/solar-akku/solar-akku-preise-kosten.html [accessed 27 January 2016].

[17] G. Hensler, "Leitfaden für effiziente Energienutzung in Industrie und Gewerbe," Bayerisches Landesamt für Umwelt, 2009. 